Sharif University of Technology
Scientia Iranica
SCIENTIA
IRAN I CA
http://scientiairanica.sharif.edu

\title{
Disability effects on daily activity type and duration
}

\author{
S. Vosough and A. Samimi* \\ Department of Civil Engineering, Sharif University of Technology, Tehran, Iran. \\ Received 25 July 2019; received in revised form 12 May 2020; accepted 7 December 2020
}

\section{KEYWORDS \\ Disability; \\ MDCEV model; \\ Activity type; \\ Activity duration; \\ Model specification.}

\begin{abstract}
Equity concerns of urban planners and policy-makers cannot be addressed unless disability effects on daily activities are disentangled. The findings, however, strongly depend on how disability is incorporated into the model. Two Multiple Discrete-Continuous Extreme Value (MDCEV) models for analyzing disability effects on daily activity type and duration are discussed and compared in this paper. In the "classic" approach, an independent dummy variable is used to distinguish disability. However, in the "separate" approach, the dataset is divided into disabled and non-disabled groups and, then, a separate model is calibrated for the disabled group. The two approaches achieve different coefficients and elasticity values, evidencing that model specification matters for policy assessments. Three transferability metrics are adopted to illustrate that the separate approach outperforms the classic approach in explaining travel patterns of persons with disabilities. Finally, three policies that have been practiced across the globe to prevent social exclusion of disabled people are discussed in terms of the effects of model specification on the policy assessment outcomes. This assessment offers managerial insights for policymakers to develop appropriate infrastructure and accessibility strategies for disabled people.

(C) 2021 Sharif University of Technology. All rights reserved.
\end{abstract}

\section{Introduction}

The World Bank reported that approximately 15 percent of the entire world population experienced disability in 2018 [1]. Persons with disabilities have different travel patterns as a result of their special physical conditions $[2,3]$. In the US, transportation difficulties keep over half a million disabled at home [4]. Other studies have also demonstrated that persons with disabilities are more likely to stay at home [57] and they have relatively lower trip rates [8,9] than the others. Those with disabilities are less likely to participate in recreational activities [10], have less

\footnotetext{
*. Corresponding author. Tel.: +98 2166164181 ; Fax: +982166014828 ;

E-mail addresses: s.hajivosough1394@student.sharif.edu (S. Vosough); asamimi@sharif.edu (A. Samimi)
}

doi: $10.24200 /$ sci.2020.54103.3590 tendency to drive [8], and are exposed to poverty [8] more than the others. These conditions reveal the limitation and exclusion that disabled population face. Hence, the United Nations compiled an international human rights treaty (the convention on the rights of persons with disabilities) to protect the rights of people with disabilities. According to this convention, policy-makers should consider the sensitivity of this vulnerable group and improve equity between various segments of society.

Studying activity and travel behavior of these segments of the population can diminish social exclusion and increase their quality of life. A handful of places in the world have conducted specific activitytravel surveys that are tailored for disabled individuals to evaluate relevant policies [11]. In fact, there is no regular travel behavior survey tailored for disabled people, primarily due to the data collection challenges. On the other hand, activity-travel surveys are regularly conducted in several cities for general transportation 
planning purposes. Such data could have several byproducts including travel behavior models for disabled people. Traditionally, dummy variables are used in general models to distinguish disability. However, a key step for studying disabled people's travel behavior is to understand how the representation of disability affects the conclusions.

Activity type and duration are two critical travel demand factors that should be systematically studied to come up with policies that target social exclusion of disabled people. MDCEV (Multiple DiscreteContinuous Extreme Value) models have been increasingly used in the past decade since they outperform the conventional formulations by jointly modeling the activity type and duration [12]. Accordingly, MDCEV family models are selected to compare disability effects on daily activity type and duration in two modeling approaches. In the "classic" approach, an independent dummy variable is used to distinguish disability, whereas the dataset is divided into disabled and nondisabled groups in the "separate" approach, and a model is directly calibrated for disabled population. The hypothesis that the classic approach and the separate approach have similar findings is evaluated in this paper. It is worth mentioning that neither the classic approach nor the separate approach is automatically profitable than the other in every research question of interest [13]. Hence, various studies have applied different approaches, especially in regression models (see [14-16] for using a category-wise separate approach over classic approach and see $[13,17,18]$ for using dummy variables over separate approach). However, to the best of our knowledge, no study has yet considered using dummy variables versus the separate approach in MDCEV models. Consequently, the goal of this study is to not only explicate the travel behavior of persons with disabilities but also compare the outcomes of the classic and separate approaches.

In the following, the relevant literature, a description of the data, and the applied MDCEV method are discussed. Then, the estimated MDCEV models, interpretation of the results, and comparisons between the classic and separate approaches are presented. Finally, the policy implications and the concluding remarks are elaborated.

\section{Background}

Travel patterns of disabled people are typically analyzed in two ways: First, general activity-travel surveys are used to estimate a model in which disability is somehow differentiated [19]. Second, specific surveys that are tailored for disabled individuals are conducted to provide detailed information on their daily activity routines [20]. Although the second class of the studies could provide valuable data and is encouraged to do so [21], a handful of cities/countries have conducted such surveys [11,22]. In fact, there is no activity-travel survey tailored for disabled people that is routinely conducted, primarily due to the data collection challenges [23].

Among the first group, several studies $[19,24,25]$ use dummy variables to distinguish disability, while other studies develop separate models for persons with disabilities by extracting disabled people observations from the regular travel data $[26,27]$. The results of the studies in which disability is differentiated by dummy variables indicate that disabled individuals have relatively few tendencies to participate in out-of-home activities such as leisure [24] and shopping [28] because of their mobility limitations. Among the separate models are Stern [26] who introduced a Poisson model to explain the activity purpose and Schmöcker et al. [27] who used an ordered Probit model to analyze different activity purposes. Stern [26] argued that walking problems declined out-of-home activity participation, except for medical purposes; Schmöcker et al. [27] also found that walking difficulties did not affect work trips. However, researchers [29] found that individuals with disabilities had impacts on crowd walking speed and mutually walking facilities had considerable impacts on the mobility of disabled people.

Among the second group of studies, on the other hand, is a study by Páez and Farber [20] who illustrated the impact of type and severity of disability on leisure activities for adults by using the 2006 Participation and Activity Limitation Survey (PALS). In another study, Ravulaparthy et al. [30] showed that disabled people who engaged in out-of-home activities reported higher levels of subjective well-being leading to a better quality of life based on data from the Disability and Use of Time (DUST), 2009.

Table 1 summarizes a selection of studies focused on activity type and/or time-use modeling for persons with disabilities. As shown in this table, very few studies have focused on activity type and duration modeling jointly. Among the joint models, no research has been specifically designed for persons with disabilities. Only in a few studies, disability status is considered as a $0 / 1$ explanatory variable to recognize how the disability affects activity patterns.

The following shortcomings recorded in the literature are identified and focused on in this study:

1. Travel behavior of disabled individuals has a rich literature, but there are very few studies that consider the interdependency of their activity type and duration;

2. Typical activity-travel surveys are occasionally adopted to explain travel behavior in general and differentiate disability with $0 / 1$ variables;

3. The coefficients of many variables are assumed 
Table 1. Summary of previous studies on activity type and duration.

\begin{tabular}{|c|c|c|c|c|c|c|c|c|c|}
\hline \multirow[b]{2}{*}{ Author(s) } & \multirow[b]{2}{*}{ Year } & \multicolumn{2}{|c|}{ Field of study } & \multirow[b]{2}{*}{ Type of activities } & \multicolumn{2}{|c|}{ Type of formulation } & \multicolumn{2}{|c|}{ Considering disability } & \multirow[b]{2}{*}{$\begin{array}{r}\text { Appliec } \\
\text { model }\end{array}$} \\
\hline & & $\begin{array}{c}\text { Activity } \\
\text { type }\end{array}$ & $\begin{array}{l}\text { Activity } \\
\text { duration }\end{array}$ & & $\begin{array}{l}\text { Conventional } \\
\text { (only one } \\
\text { decision) }\end{array}$ & $\begin{array}{c}\text { Joint } \\
\text { decisions }\end{array}$ & $\begin{array}{c}\text { Dummy in } \\
\text { a general } \\
\text { model }\end{array}$ & $\begin{array}{c}\text { Separate model } \\
\text { for the } \\
\text { disabled }\end{array}$ & \\
\hline Stern & 1993 & $\sqrt{ }$ & - & $\begin{array}{l}\text { Work/school, } \\
\text { shopping, } \\
\text { medical, } \\
\text { recreation } \\
\text { and others }\end{array}$ & $\sqrt{ }$ & - & - & $\sqrt{ }$ & Poisson \\
\hline $\begin{array}{l}\text { Schmöcker } \\
\text { et al. }\end{array}$ & 2005 & $\sqrt{ }$ & - & $\begin{array}{l}\text { Work, shopping, } \\
\text { personal business, } \\
\text { and recreational }\end{array}$ & $\sqrt{ }$ & - & - & $\sqrt{ }$ & $\begin{array}{l}\text { Ordinal } \\
\text { probit }\end{array}$ \\
\hline Bhat et al. & 2006 & $\sqrt{ }$ & $\sqrt{ }$ & $\begin{array}{l}\text { Non-work and } \\
\text { non-school } \\
\text { activities }\end{array}$ & - & $\sqrt{ }$ & $\sqrt{ }$ & - & MDCEV \\
\hline Pinjari et al. & 2009 & $\sqrt{ }$ & $\sqrt{ }$ & $\begin{array}{l}\text { Non-work and } \\
\text { non-school } \\
\text { activities }\end{array}$ & - & $\sqrt{ }$ & $\sqrt{ }$ & - & MDCEV \\
\hline $\begin{array}{l}\text { Pinjari } \\
\text { and Bhat }\end{array}$ & $2010 \mathrm{a}$ & $\sqrt{ }$ & $\sqrt{ }$ & $\begin{array}{l}\text { Activities of } \\
\text { non-worker people } \\
\text { at the weekends }\end{array}$ & - & $\sqrt{ }$ & $\sqrt{ }$ & - & MDCEV \\
\hline $\begin{array}{l}\text { Páez } \\
\text { and Farber }\end{array}$ & 2012 & $\sqrt{ }$ & - & $\begin{array}{l}\text { Various } \\
\text { discretionary } \\
\text { activities }\end{array}$ & $\sqrt{ }$ & - & - & $\sqrt{ }$ & $\begin{array}{l}\text { Ordinal } \\
\text { probit }\end{array}$ \\
\hline $\begin{array}{l}\text { Shabanpour } \\
\text { et al. }\end{array}$ & 2017 & $\sqrt{ }$ & $\sqrt{ }$ & $\begin{array}{l}\text { Sleep, personal } \\
\text { maintenance } \\
\text { household, } \\
\text { maintenance, } \\
\text { leisure, } \\
\text { discretionary, } \\
\text { and mandatory }\end{array}$ & - & $\sqrt{ }$ & $\sqrt{ }$ & - & $\begin{array}{l}\text { Copula } \\
\text { based }\end{array}$ \\
\hline
\end{tabular}

similar among disabled people and others, except for very few variables that are differentiated with dummy variables.

Despite some limitations in this study, we attempt to address the aforementioned shortcomings.

\section{Data}

The data collected in the Household Travel Survey by the Atlanta Regional Commission were used in this study because:

1. The paper aimed at analyzing the traditional activity-travel data differently and provided a better explanation for travel behavior of disabled people;

2. The data is available for free and the results could be reproduced and verified.
In this survey, one-day activity and travel information were collected from 10,278 households including 25,810 persons with 93,713 trips in 2011 [31]. Around 5.2 percent of the sample was identified as persons with disabilities including limited mobility (37.2 percent), mental disabilities (10.4 percent), visual impairment (8.9 percent), and hearing impairment (1.4 percent).

Twenty-five activity purposes were defined in the original data [32]. In this study, activities are aggregated and classified into 6 groups: (1) in-home $(\mathrm{H}),(2)$ work/school (W), (3) healthcare (HC), (4) shopping $(\mathrm{SH}),(5)$ recreational $(\mathrm{R})$, and $(6)$ other $(\mathrm{O})$ activities. All the households reported 119,480 activities, among which disabled people conducted 4,363 (3.65 percent). The numbers of people that reported each activity along with the average duration of each activity are presented in Table 2. It can be observed that the average time that persons with disabilities spend on in-home activities is about 1.25 times higher than all the people. Also, the average time that persons with disabilities 
Table 2. Descriptive statistics of daily activity type participation and duration.

\begin{tabular}{|c|c|c|c|c|}
\hline \multirow{2}{*}{$\begin{array}{l}\text { Activity } \\
\text { type }\end{array}$} & \multicolumn{2}{|c|}{ Persons with disabilities } & \multicolumn{2}{|c|}{ All people } \\
\hline & $\begin{array}{c}\text { Number (percent) } \\
\text { of individuals* }\end{array}$ & $\begin{array}{l}\text { Mean activity } \\
\text { duration (min) }\end{array}$ & $\begin{array}{c}\text { Number (percent) } \\
\text { of individuals* }\end{array}$ & $\begin{array}{l}\text { Mean activity } \\
\text { duration (min) }\end{array}$ \\
\hline In-home & $1137(100)$ & 1253 & $16799(100)$ & 1001 \\
\hline Work/school & $113(9.9)$ & 40 & $9614(57.2)$ & 254 \\
\hline Health care & $189(16.6)$ & 24 & $1224(7.3)$ & 10 \\
\hline Shopping & $268(23.6)$ & 18 & $4878(29.0)$ & 15 \\
\hline Recreation & $238(20.9)$ & 36 & $5834(34.7)$ & 47 \\
\hline Other & $316(27.8)$ & 19 & $6986(41.6)$ & 29 \\
\hline
\end{tabular}

*Sum of percentages in the column do not equal to 100 because some individuals participate in more than one activity type.

allocate to healthcare activities is more than twice of all the people. The portion of persons with disabilities who participated in work/school activities is about five times less than all the people. Also, Table 3 provides a description and definition of household and individual socio-demographic variables used in this study.

\section{Method and model}

Joint models are increasingly used for activity and travel-related decisions since several studies have found that joint formulations outperform the conventional ones where decisions are interdependent [33-36]. Particularly, several studies $[37,38]$ have argued the benefits of joint model specifications for activity type and duration models. Thus, MDCEV formulation [39] that allows modeling the choice of multiple activity types while accounting for the duration of each activity over a day is adopted in this study. MDCEV models are widely used in transportation-related studies including carsharing vehicle choice and usage [40], household vehicle ownership [41,42], transportation expenditures [43], and energy consumption [44]. Bhat [45] formulated the utility function for an individual as in Eq. (1) for $K$ different activities, where, $\alpha_{k}$ and $\gamma_{k}$ are satiation and translation parameters associated with activity $k$, respectively, $x_{k}$ is the corresponding consumption quantity of activity $k\left(x_{k} \leq 0\right.$ for all $(\mathrm{k}), \beta_{k}$ is the coefficient vector related to activity $k, z_{k}$ is the vector of attributes for activity $k$, and $\epsilon_{k}$ is the unobserved characteristics of activity $k$ that impacts the baseline utility.

$$
\begin{gathered}
U(x)=\sum_{k=1}^{K} \frac{\gamma_{k}}{\alpha_{k}}\left[\exp \left(\beta_{k}^{\prime} z_{k}+\varepsilon_{k}\right)\right] \cdot\left[\left(\frac{x_{k}}{\gamma_{k}}+1\right)^{\alpha_{k}}-1\right] \\
\alpha_{k} \leq 1 \text { and } \gamma_{k}>0 \text { for all } k
\end{gathered}
$$

Each person maximizes his/her utility given a time budget formulated as $\sum_{k=1}^{K} e_{k}=E$, where $E$ is the total available time and $e_{k}$ is the expenditure on activity $k$ (note that $e_{k}=p_{k} \cdot x_{k}$ and $p_{i}$ is the unit price of activity $k$, which is set to $1 \mathrm{in}$ this study). To determine the optimal time allocated to each activity type, the Lagrangian function is formed and the Kuhn-Tucker conditions are applied. If an "outside good" (such as in-home activity which is selected by everyone) exists, the utility function is formed as follows [45], assuming that the first activity is the outside good:

$$
\begin{aligned}
U(x)= & \frac{1}{\alpha_{1}} \exp \left(\varepsilon_{1}\right) \cdot\left(x_{1}\right)^{\alpha_{1}}+\sum_{k=2}^{K} \frac{\gamma_{k}}{\alpha_{k}} \\
& {\left[\exp \left(\beta_{k}^{\prime} z_{k}+\varepsilon_{k}\right)\right] \cdot\left[\left(\frac{x_{k}}{\gamma_{k}}+1\right)^{\alpha_{k}}-1\right] . }
\end{aligned}
$$

Bhat [45] argued that $\alpha_{k}$ and $\gamma_{k}$ were empirically difficult to identify since both of them capture satiation effects. Hence, the utility function would be replaced with the following three forms:

$$
\begin{aligned}
U(x)= & \frac{1}{\alpha_{1}} \exp \left(\varepsilon_{1}\right) \cdot\left(x_{1}\right)^{\alpha_{1}} \\
& +\sum_{k=2}^{K} \frac{1}{\alpha_{k}}\left[\exp \left(\beta_{k}^{\prime} z_{k}+\varepsilon_{k}\right)\right] \cdot\left[\left(x_{k}+1\right)^{\alpha_{k}}-1\right] \\
U(x)= & \frac{1}{\alpha_{1}} \exp \left(\varepsilon_{1}\right) \cdot\left(x_{1}\right)^{\alpha_{1}} \\
& +\sum_{k=2}^{K} \gamma_{k}\left[\exp \left(\beta_{k}^{\prime} z_{k}+\varepsilon_{k}\right)\right] \cdot\left[\left(\frac{x_{k}}{\gamma_{k}}+1\right)^{-1}\right] \\
U(x)= & \frac{1}{\alpha} \exp \left(\varepsilon_{1}\right) \cdot\left(x_{1}\right)^{\alpha} \\
& +\sum_{k=2}^{K} \frac{\gamma_{k}}{\alpha}\left[\exp \left(\beta_{k}^{\prime} z_{k}+\varepsilon_{k}\right)\right] \cdot\left[\left(\frac{x_{k}}{\gamma_{k}}+1\right)^{\alpha}-1\right]
\end{aligned}
$$


Table 3. Description of explanatory variables used in models.

\begin{tabular}{|c|c|c|c|c|c|c|c|}
\hline \multirow{2}{*}{ Variable } & \multirow{2}{*}{ Definition } & \multicolumn{2}{|c|}{ Disabled } & \multicolumn{2}{|c|}{ Non-disabled } & \multicolumn{2}{|c|}{ Whole sample } \\
\hline & & Mean & SE & Mean & SE & Mean & SE \\
\hline URBAN & $\begin{array}{l}\text { Being urban residential: } 1 \text {, } \\
\text { otherwise: } 0\end{array}$ & 0.03 & 0.17 & 0.03 & 0.16 & 0.03 & 0.16 \\
\hline DIS-URBN & $\begin{array}{l}\text { A person with disability } \\
\text { living in urban area: } 1 \text {, } \\
\text { otherwise: } 0 \text {. }\end{array}$ & - & - & - & - & 0.001 & 0.04 \\
\hline RENT & $\begin{array}{l}\text { Having rented house: } 1 \text {, } \\
\text { otherwise: } 0\end{array}$ & 0.36 & 0.48 & 0.13 & 0.33 & 0.14 & 0.35 \\
\hline HHSIZ & Household size & 2.60 & 1.31 & 3.23 & 1.48 & 3.20 & 1.48 \\
\hline DHHVEH & $\begin{array}{l}\text { Having vehicle(s) } \\
\text { in household: } 1 \text {, } \\
\text { otherwise: } 0\end{array}$ & 0.83 & 0.38 & 0.98 & 0.14 & 0.97 & 0.16 \\
\hline LOWINC & $\begin{array}{l}\text { Household income, } \\
\text { less than } \$ 20,000 \text { : } 1 \text {, } \\
\text { otherwise: } 0\end{array}$ & 0.35 & 0.48 & 0.07 & 0.26 & 0.09 & 0.28 \\
\hline HHCHD & $\begin{array}{l}\text { Number of children } \\
\text { in household }\end{array}$ & 1.70 & 0.99 & 1.06 & 1.24 & 1.10 & 1.23 \\
\hline LIFESTYLE & $\begin{array}{l}2+\text { adults, at least } \\
\text { one retired, } \\
\text { no children: } 1 \text {, } \\
\text { otherwise: } 0\end{array}$ & 0.35 & 0.48 & 0.13 & 0.34 & 0.14 & 0.35 \\
\hline DISBLTY & $\begin{array}{l}\text { person with disability: } 1 \text {, } \\
\text { otherwise: } 0\end{array}$ & - & - & - & - & 0.05 & 0.22 \\
\hline MALE & $\begin{array}{l}\text { Gender; } 1 \text { : male, } \\
0 \text { : female }\end{array}$ & 0.40 & 0.49 & 0.47 & 0.50 & 0.47 & 0.50 \\
\hline $\mathrm{AGE}$ & Age of a person & 55.87 & 19.02 & 38.95 & 21.33 & 39.83 & 21.54 \\
\hline DISB-AGE & $\begin{array}{l}\text { Interaction of age } \\
\text { and disability. }\end{array}$ & - & - & - & - & 2.91 & 13.15 \\
\hline LICENSE & $\begin{array}{l}\text { Having driving } \\
\text { license: } 1 \text {, } \\
\text { otherwise: } 0\end{array}$ & 0.63 & 0.48 & 0.95 & 0.23 & 0.93 & 0.26 \\
\hline WALK & $\begin{array}{l}\text { Having difficulty } \\
\text { walking: } 1 \text {, } \\
\text { otherwise: } 0\end{array}$ & 0.37 & 0.48 & - & - & 0.02 & 0.14 \\
\hline EMPLY & $\begin{array}{l}\text { Employed: } 1 \text {, } \\
\text { otherwise: } 0 .\end{array}$ & 0.10 & 0.29 & 0.64 & 0.48 & 0.61 & 0.49 \\
\hline
\end{tabular}


Table 3. Description of explanatory variables used in models (continued).

\begin{tabular}{|c|c|c|c|c|c|c|c|}
\hline \multirow{2}{*}{ Variable } & \multirow{2}{*}{ Definition } & \multicolumn{2}{|c|}{ Disabled } & \multicolumn{2}{|c|}{ Non-disabled } & \multicolumn{2}{|c|}{ Whole sample } \\
\hline & & Mean & SE & Mean & SE & Mean & SE \\
\hline WORKER & $\begin{array}{l}\text { Worker: } 1 \text {, } \\
\text { otherwise: } 0 .\end{array}$ & 0.13 & 0.34 & 0.69 & 0.46 & 0.65 & 0.48 \\
\hline DISB-WRK & $\begin{array}{l}\text { A person with } \\
\text { disability who works: } 1 \text {, } \\
\text { otherwise: } 0 .\end{array}$ & - & - & - & - & 0.01 & 0.09 \\
\hline HIDEU & $\begin{array}{l}\text { Having undergraduate } \\
\text { /graduate degree: } 1, \\
\text { otherwise: } 0 .\end{array}$ & 0.19 & 0.39 & 0.40 & 0.49 & 0.39 & 0.49 \\
\hline STUDNT & $\begin{array}{l}\text { Being student: } 1 \text {, } \\
\text { otherwise: } 0 .\end{array}$ & 0.08 & 0.27 & 0.28 & 0.45 & 0.27 & 0.44 \\
\hline DIS-STUD & $\begin{array}{l}\text { A person with } \\
\text { disability who is a student: } 1 \text {, } \\
\text { otherwise: } 0 .\end{array}$ & - & - & - & - & 0.004 & 0.06 \\
\hline EVERYDAY & $\begin{array}{l}\text { Using public transit, } \\
\text { nearly every day: } 1 \text {, } \\
\text { otherwise: } 0 .\end{array}$ & 0.06 & 0.23 & 0.03 & 0.18 & 0.03 & 0.18 \\
\hline MONTH & $\begin{array}{l}\text { Using public transit, } \\
\text { once or twice a month: } 1 \text {, } \\
\text { otherwise: } 0 .\end{array}$ & 0.07 & 0.26 & 0.07 & 0.25 & 0.07 & 0.25 \\
\hline DIS-MONTH & $\begin{array}{l}\text { A person with disability } \\
\text { who uses public transit } \\
\text { once or twice a month: } 1 \text {, } \\
\text { otherwise: } 0 \text {. }\end{array}$ & - & - & - & - & 0.005 & 0.07 \\
\hline NTRIPS & $\begin{array}{l}\text { Number of person's trips } \\
\text { in a day. }\end{array}$ & 2.32 & 2.72 & 3.75 & 2.78 & 3.68 & 2.79 \\
\hline
\end{tabular}

The probability of the expenditure of the first $M$ out of $K$ activities (with the outside good at first) is shown in Eq. (4) [45]:

$$
\begin{aligned}
P( & \left.x_{1}^{*}, x_{2}^{*}, x_{3}^{*}, \ldots, x_{M}^{*}, 0,0, \ldots, 0\right) \\
= & \frac{1}{\sigma^{M-1}}\left[\prod_{i=1}^{M} c_{i}\right]\left[\sum_{i=1}^{M} \frac{p_{i}}{c_{i}}\right]\left[\frac{\prod_{i=1}^{M} e^{V_{i} / \sigma}}{\left(\sum_{k=1}^{K} e^{V_{k} / \sigma}\right)^{M}}\right] \\
& (M-1) !
\end{aligned}
$$

where $\sigma$ is the scale parameter set to 1 for convenience [45], $V_{i}$ is related to Kuhn-Tucker conditions estimated by Eq. (5) according to the selected form of the three utility functions; and $c_{i}=\frac{1-\alpha_{i}}{x_{i}^{*}+\gamma_{i}}$ :

$$
\begin{gathered}
V_{k}=\beta_{k}^{\prime} z_{k}+\left(\alpha_{k}-1\right) \cdot \ln \left(x_{k}^{*}+1\right)-\ln \left(p_{k}\right) \\
k \geq 2, \quad V_{1}=\left(\alpha_{1}-1\right) \ln \left(x_{1}^{*}\right),
\end{gathered}
$$

$$
\begin{aligned}
& V_{k}=\beta_{k}^{\prime} z_{k}-\ln \left(\frac{x_{k}^{*}}{\gamma_{k}}+1\right)-\ln \left(p_{k}\right) \\
& k \geq 2, \quad V_{1}=\left(\alpha_{1}-1\right) \ln \left(x_{1}^{*}\right), \\
& V_{k}=\beta_{k}^{\prime} z_{k}+(\alpha-1) \cdot \ln \left(\frac{x_{k}^{*}}{\gamma_{k}}+1\right)-\ln \left(p_{k}\right) \\
& k \geq 2, \quad V_{1}=\left(\alpha_{1}-1\right) \ln \left(x_{1}^{*}\right) .
\end{aligned}
$$

Regarding these constraints, Bhat introduced five specifications [46] to estimate the MDCEV model while accounting for estimation of, at last, one parameter between $\alpha$ and $\gamma$. Recently, this limitation was addressed by Shamshiripour and Samimi [47] that would make the simultaneous estimation of both parameters readily possible. However, in this study, the five traditional specifications (as shown in Table 4) are adopted for all the observations in which disability is differentiated with a $0 / 1$ variable (the classic approach). Then, all specifications are again calibrated only for the observations with disabilities (the separate 
Table 4. Multi Discrete-Continuous Extreme Value (MDCEV) Specifications with outside good.

\begin{tabular}{ccccc}
\hline Specification & $\begin{array}{c}\boldsymbol{\alpha} \text { for } \\
\text { outside good }\end{array}$ & $\begin{array}{c}\boldsymbol{\alpha} \text { for } \\
\text { other goods }\end{array}$ & $\begin{array}{c}\boldsymbol{\gamma} \text { for } \\
\text { outside good }\end{array}$ & $\begin{array}{c}\boldsymbol{\gamma} \text { for } \\
\text { other goods }\end{array}$ \\
\hline 1 & is estimated & is estimated & $-{ }^{*}$ & is fixed to 1 \\
2 & is fixed to 0 & is fixed to 0 & - & is estimated \\
3 & All are constrained to be equal and estimated & - & is estimated \\
4 & is estimated & is fixed to 0 & - & is estimated \\
5 & is fixed to 0 & is fixed to 0 & - & is fixed to 1 \\
\hline
\end{tabular}

*There is no gamma for outside good because it is always used.

Table 5. Results of different specifications.

\begin{tabular}{|c|c|c|c|c|c|c|}
\hline \multirow{2}{*}{ Approach } & \multirow{2}{*}{ Criteria } & \multicolumn{5}{|c|}{ Specifications } \\
\hline & & 1 & 2 & 3 & 4 & 5 \\
\hline \multirow{4}{*}{ Classic approach } & Log likelihood value & $-230,300$ & $-216,851$ & $-216,851$ & $-216,851$ & $-273,928$ \\
\hline & $\mathrm{BIC}$ & 461,195 & 434,286 & 434,296 & 434,296 & 548,392 \\
\hline & $\begin{array}{l}\text { Likelihood ratio test } \\
\text { (specification } 5 \text { is the base) }\end{array}$ & 872,56 & 114,155 & 114,155 & 114,155 & 0 \\
\hline & Number of parameters & 61 & 60 & 61 & 61 & 55 \\
\hline \multirow{4}{*}{ Separate approach } & Log likelihood value & $-9,029$ & $-8,459$ & $-8,459$ & $-8,459$ & $-107,04$ \\
\hline & $\mathrm{BIC}$ & 18,418 & 17,271 & 17,278 & 17,278 & 21,725 \\
\hline & $\begin{array}{l}\text { Likelihood ratio test } \\
\text { (specification } 5 \\
\text { is the base) }\end{array}$ & 3,349 & 4,489 & 4,489 & 4,489 & 0 \\
\hline & Number of parameters & 51 & 50 & 51 & 51 & 45 \\
\hline
\end{tabular}

approach). The best specification of each approach was selected through the log-likelihood values, likelihood values, likelihood ratio test (with the likelihood of the 5 th specification, where $\alpha$ and $\gamma$ are set to zero, serves as the benchmark), and Bayesian Information Criterion (BIC) index. As shown in Table 5, the 2nd specification, where $\alpha$ is fixed to zero for all activities and $\gamma$ is estimated, outperforms the other specifications in both approaches, since it has a higher likelihood value than the 1 st and 5 th specifications and also a lower BIC index than the 3rd and 4th specifications. The results of this specification for the classic and separate models are discussed in the following section.

\section{Results}

ratio test (with the likelihood of the 5 th specification, where $\alpha$ and $\gamma$ are set to zero, serves as the benchmark), and Bayesian Information Criterion (BIC) index. As shown in Table 5, the 2nd specification, where $\alpha$ is fixed to zero for all activities and $\gamma$ is estimated, outperforms the other specifications in both approaches, since it has a higher likelihood value than the 1 st and 5th specifications and also a lower BIC index than the 3rd and 4 th specifications. The results of this specification for the classic and separate models are discussed in the following section.

The results of classic and separate approaches are compared to investigate the potential advantages of the separate approach over the classic approach. Accordingly, the difference in coefficients and elasticity values along with three conventional transferability tests are discussed. Finally, the separate approach results are interpreted.

\subsection{Comparison of the models}

The results of the classic and separate approaches are presented in Tables 6 and 7 . To evaluate the difference between these two approaches, the statistical significance and p-value of differences between the comparable coefficients of the classic and separate approaches are presented in Table 8 . Most of the coefficients are statistically different at a level of 90 percent. For instance, the difference between AGE coefficients in the healthcare activity $(\mathrm{HC})$ of the classic and the separate approaches is 0.027 with a standard error of 0.01 , which shows statistical significance at a level of 99 percent. As shown in Table 8, many coefficients including NTRIPS, STUDNT, HHCHD, and URBAN are statistically different, while some variables such as MALE, LICENSE, and HIEDU have similar coefficients.

The differences in elasticity values are reported in Table 9 to illustrate how the changes in model coefficients could lead to different policy assessments. The elasticity is calculated by the percentage of change in allocated time to an activity after increasing a continuous independent variable by one percent, increasing a count variable by one unit, or changing a dummy variable from 0 to 1 . The latter is called pseudo-elasticity 

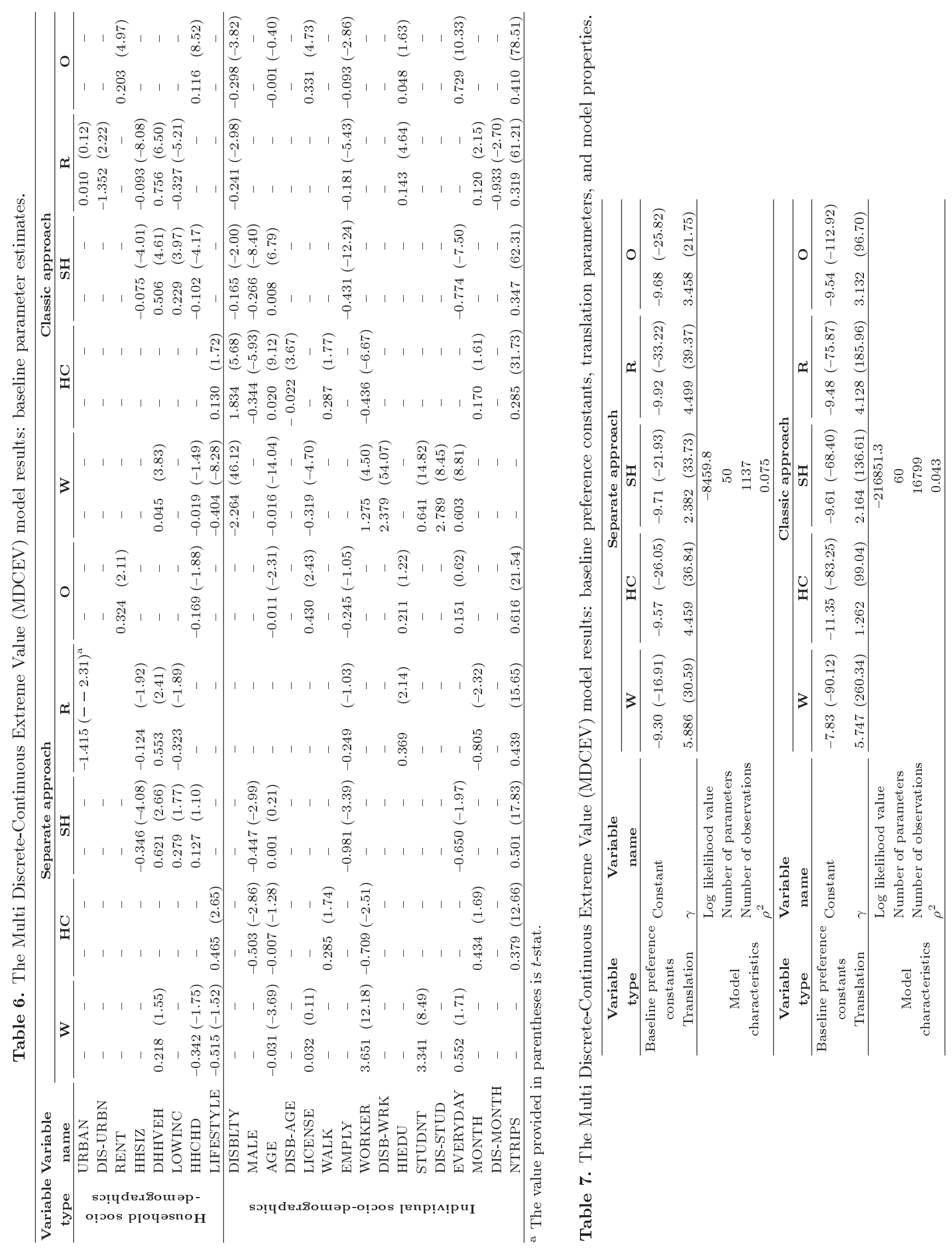


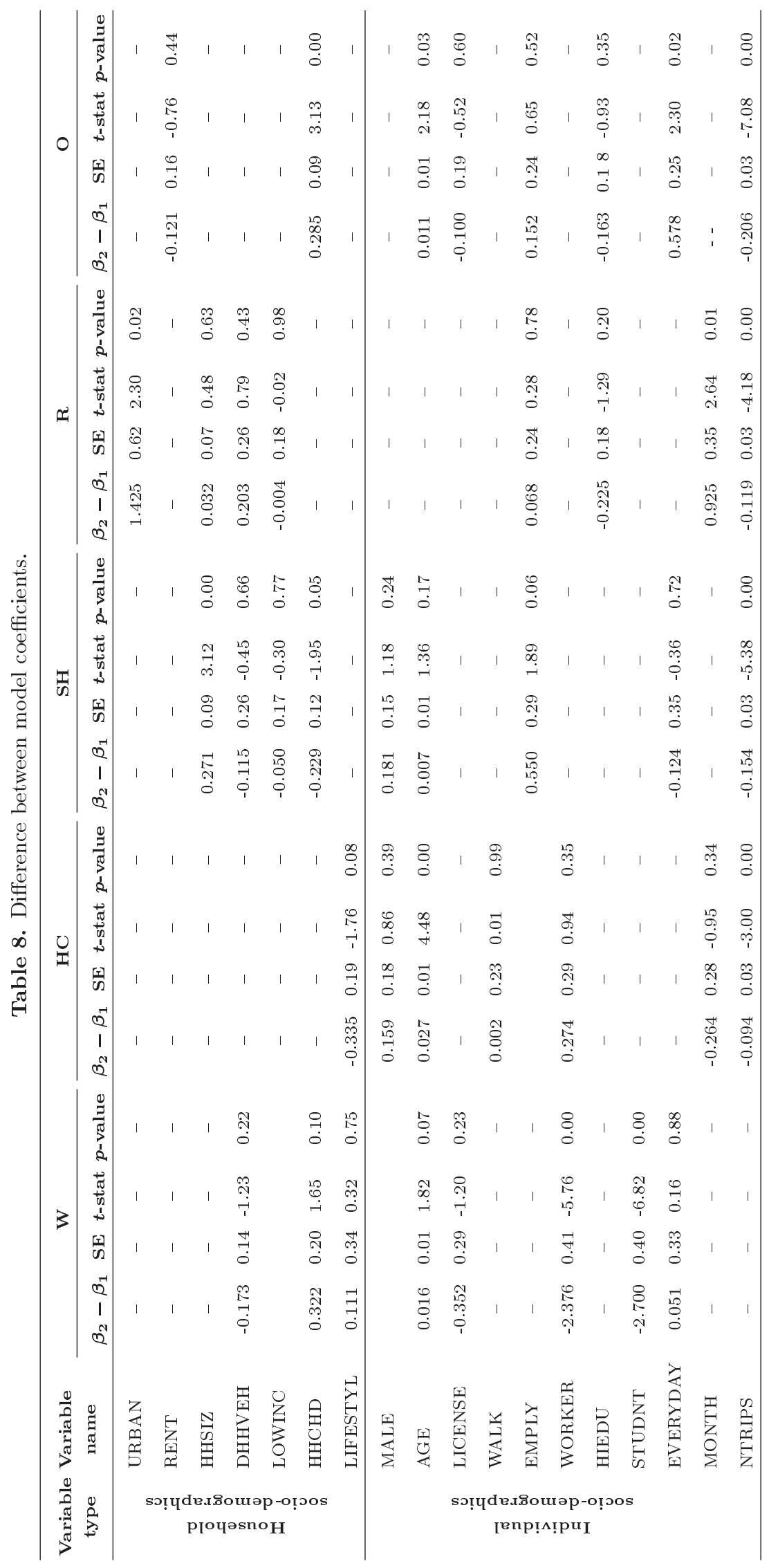




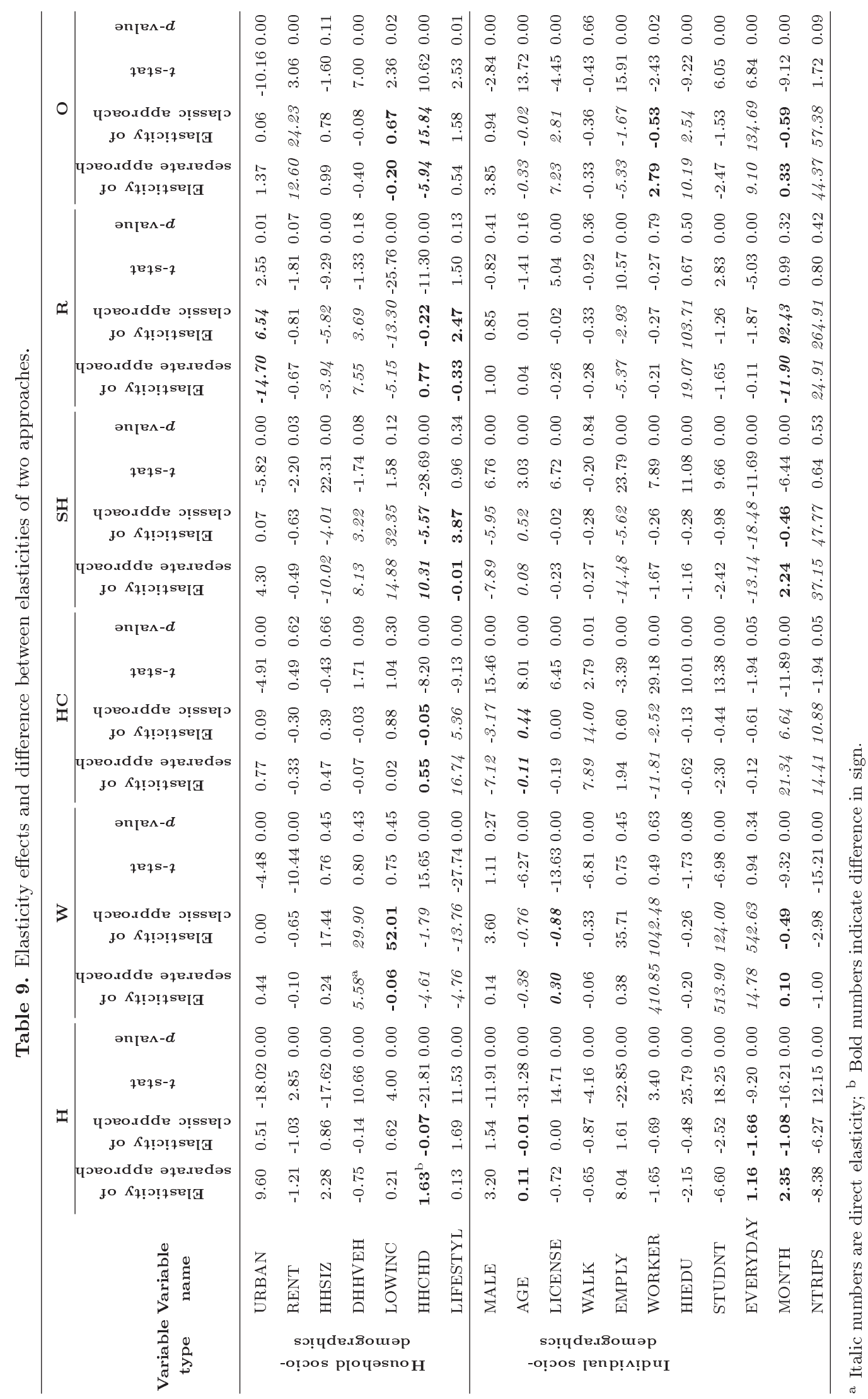


which is not accurate since derivative values are reliable only in the vicinity of the observed point, but its relative magnitude of the two approaches could be informative. For predicting the time allocated to each activity with the MDCEV model, before and after changing a variable, an algorithm introduced by Pinjari and Bhat [48] is applied. The percentage of change in activity duration due to a change in a specific independent variable is also reported in Table 9. Most of the elasticities are statistically different at a level of 90 percent. For instance, having academic education has a stronger effect on reducing healthcare activities in the separate approach than the classic one $(-0.62$ versus -0.13). Similarly, the effect of having at least one vehicle in the household on the participation of persons with disabilities in shopping activities is 2.5 times stronger in the separate approach than the classic one.

Model transferability metrics could evaluate the ability of a transferred model in explaining the behaviors of the model for a new data set. Three conventional transferability measures namely Transferability Test Statistic (TTS), Transfer Index (TI), and the Transfer Rho-square $\left(\rho^{2}\right)$ affirm that the separate model could not be replaced by the classic model.

Atherton and Ben-Akiva [49] defined the TTS as in Eq. (6):

$$
T T S_{j}=-2\left(L L_{j}\left(\theta_{i}\right)-L L_{j}\left(\theta_{j}\right)\right),
$$

where $L L_{j}\left(\theta_{i}\right)$ is the log-likelihood value estimated by observed data $j$ and the transferred model coefficients $i$, and $L L_{j}\left(\theta_{i}\right)$ is the log-likelihood value estimated by observed data $j$ and the model coefficients $j$. In this case, $j$ refers to the separate model for persons with disabilities and $i$ is a representative of the classic model which includes all observations from the data set. Accordingly, the TTS value would be 492. Given that TTS follows Chi-square distribution with degrees of freedom equal to the number of parameters, the hypothesis that the classic model could be transferred to disabled people is rejected at a significance level of 95 percent.

TI, introduced by Koppelman and Wilmot [50], has an upper limit of one (i.e., the transferred model is as accurate as the local one) and is calculated by Eq. (7):

$$
T I_{j}\left(\theta_{i}\right)=\frac{L L_{j}\left(\theta_{i}\right)-L L_{j}(C)}{L L_{j}\left(\theta_{j}\right)-L L_{j}(C)},
$$

where $L L_{j}(C)$ is the log-likelihood value of the model $j$ estimated with constants only, and $L L_{j}\left(\theta_{i}\right)$ and $L L_{j}\left(\theta_{j}\right)$ have similar definitions to the TTS metric. The TI value for the classic model is computed to be 0.64 . This means that the classic model $(i)$ is less fit for the travel behavior of persons with disabilities than the separate model.
The transfer Rho-square $\left(\rho^{2}\right)$ is the third transferability measure which is analogous to the commonly used Rho-squared measure [51] and is obtained by Eq. (8):

$$
\rho_{j}^{2}\left(\theta_{i}\right)=1-\frac{L L_{j}\left(\theta_{i}\right)}{L L_{j}(C)},
$$

$\rho^{2}$ is upper bounded by the local Rho-squared. However, in this case, its value is 0.048 which is considerably lower than that of the separate model (0.075). The threefold comparisons discussed in this section reveal that the separate approach has different coefficients and policy outcomes and outperforms the classic approach in explaining the travel patterns of persons with disabilities.

\subsection{Interpretation of the results}

The separate MDCEV model, as the superior model, is interpreted in this section. This includes discussions on the effects of household socio-demographics on baseline utility, effects of individual socio-demographics on baseline utility, baseline preference constants, and translation parameters.

Household socio-demographics, including lifestyle, residence area type, household income, household size, vehicle ownership, and the number of children, turned out to be statistically significant in the baseline utility. Understandably, persons with disabilities who live in urban areas spend less time on recreational activities than disabled persons who live in other areas. Disabled individuals in large families have a lower propensity to participate in shopping activities. This consequence reflects that the presence of other people for doing maintenance shopping prevents disabled individuals from shopping.

They are also less likely to spend time on recreational activities. Pinjari and Bhat (2010) [28] also came up with the same outcomes, showing that nonworkers spend less time on out-of-home discretionary activities in larger families. However, by increasing the number of children, preference for shopping activities among persons with disabilities rises. In this case, if the disabled person is a parent, he/she is responsible for doing shopping and if the disabled person is a child, he/she might be accompanied by other children and parents. As a result, the probability of spending time on shopping activities increases. Further, disabled individuals are more likely to have work/school, shopping, and recreational activities in families with at least one vehicle due to the flexibility and improved access to private mode. In low-income households, disabled individuals tend to have fewer recreational activities. Bhat (2005) [39], also, argued that higher income would reinforce the ability to participate in outof-home recreational activities. Interestingly, persons with disabilities in low-income families are more likely 
to spend time on shopping activities. It is commonly believed that a person with disability in a low-income family will need some more time to find good deals for mandatory shopping, e.g., grocery than those in high-income households. Online shopping and hiring someone to do their shopping might be unattainable to disabled people in low-income families, as well. Finally, less tendency for work/school and more propensity for healthcare activities are observed in families with more than two adults, at least one retired, and no children.

Individual socio-demographics such as age, gender, education, having a driving license, and employment status have remarkable effects on the activity patterns of disabled people. Elderly persons with disabilities, for instance, are less inclined toward working. According to Table 9, work activities decline by 0.38 percent as age increases by 1 percent. Males with disabilities are less likely to have shopping or healthcare activities than disabled females. This is in line with the findings of Pinjari and Bhat (2010) [28]. Further, persons with disabilities who rarely use public transport spend much time on healthcare activities and participate less in recreational activities. These results could be arguably attributed to their mobility limitations. In contrast, disabled people who often use public transport are more likely to participate in work activities. This might be due to either better physical condition of the disabled person or better access to adjusted public transport. Among disability types, walking difficulty results in more participation in healthcare activities. However, there is no significant effect found for other types of disability, possibly due to their limited observations in the data. On the contrary, persons with disabilities who work are less inclined to spend time on healthcare activities. Indeed, being a worker/employment has an adverse effect on participating in all activity types except for work/school. This result is consistent with what Pinjari et al. (2009) [25] concluded. Furthermore, people with disabilities with an academic degree participate more in recreational activities.

The baseline preference constants are representatives of the general preference for each activity type relative to the base category (i.e., in-home activity). In this study, all the baseline preference constants are negative, meaning that in-home activity is most preferred and all individuals participate in it. Also, at a point when no time has yet been spent in any activity type, the least preferred activity purpose among persons with disabilities is recreation because it has the lowest value among baseline preference constants.

The translation parameters $\left(\gamma_{k}\right)$ for all activity types (except for in-home as the outside good) and the corresponding t-stats are provided in Table 7 . The magnitude of the parameter $\gamma_{k}$ is inversely related to the satiation effect for activity purpose $k$. Therefore, a value of $\gamma$ closer to zero results in higher satiation and, consequently, the lower time consumed in activity type $k$. The results indicate that the shortest activity duration among persons with disabilities is shopping, meaning that this activity has the highest satiation effects. On the other hand, the lowest satiation effect belongs to work/school activities that is understandable for mandatory activities.

\section{Policy implication}

An essential application of travel pattern models for disabled people is to evaluate potential policies that could prevent their social exclusion. Policy-sensitive variables in the proposed models include income, residential area type, having a driving license, employment status, level of education, and public transport usage. Among these, vehicle ownership, public transport usage, and education are of particular interest since the classic and the separate approaches provide different policy outcomes. These are discussed in more detail in this section.

Improving access to auto vehicles could patronize disabled individuals to participate in out-of-home activities. Recently, theoretical studies have also analyzed the effect of using a private automated vehicle that significantly improves the accessibility for persons with disabilities $[52,53]$. Thus, policymakers who wish to encourage persons with disabilities to participate in such activities should find methods to think about relevant vehicle ownership policies. Queensland authorities in Australia, for instance, offer special subsidies so that disabled people could purchase or modify a car for their special needs through the vehicle options subsidy scheme [54]. To justify the budget for such programs, policy-makers need to be aware of the impacts on travel-activity patterns of the disabled. The preferred model specification could strongly affect policy assessment outcomes. As shown in Table 9, for example, shopping and recreational activities drastically increase, if a household has access to a private automobile. However, the magnitude of this change is 2 and 2.5 times higher for recreational and shopping activities, respectively, in the separate approach than the classic approach. Thus, the benefits of this program in terms of promoting shopping and recreational activities would be underestimated if the classic approach is adopted instead of the separate approach. Similar arguments could be made for other variables, as well.

Promoting public transport use for disabled people is a concern among many city officials since several studies proved that persons with disabilities have much higher reliance on public transportation to make trips $[55,56]$ and barriers of public transportation stop people with disabilities to participate in society [57]. The 
West Virginia Country Roads Transit (CRT) modified buses and vans with wheelchair lifts or ramps to meet the needs of persons with disabilities who use public transportation. Operators are trained to assist persons with disabilities, secure wheelchairs, provide information on destinations, and announce stops [58]. Training programs for persons with disabilities can also improve the overall skills needed for using public transportation [59]. Similarly, model specification plays a key role in ensuring the success of policy assessments. As shown in Table 9, those who regularly use public transport are less likely to have healthcare activities. However, the effect of using public transport on healthcare activity participation is 5 times higher in the classic approach than the separate one. There are opposite signs in elasticity results in some cases. For instance, Table 9 illustrates that if all persons with disabilities use public transportation rarely, their participation in recreational activities will reduce by 11.9 percent. However, under this circumstance, the classic approach surprisingly shows a 92.4 percent increase in recreational activities.

Facilitating higher education for disabled people is another policy to prevent social exclusion. Some countries ratified the 1960 UNESCO's Convention Against Discrimination in Education (CADE) in support of providing better education for disabled people. Some actions are taken in different countries to give persons with disabilities a greater chance of education such as allocating the grant to students with permanent disabilities in Canada [60]. Likewise, the University of Iowa offers door-to-door transit services for students with disabilities called CAMBUS [61]. Again, such policies need to be justified based on facts and figures. As demonstrated in Table 9, if all persons with disabilities have an undergraduate/graduate degree, healthcare activities drop 4.8 times more in the separate approach than in the classic approach $(-0.62$ versus -0.13 ). Therefore, making decisions based on the separate model for persons with disabilities would result in different policy evaluations.

\section{Conclusion}

Household travel surveys showed that individuals with disabilities participated in fewer out-of-home activities. Hence, they are at a higher risk of depression, poverty, and other socio-economic damages. A better picture of their travel behavior might enable the decisionmakers to help them engage in various out-of-home activities. This study is an attempt to explore the impact of the way that disability is modeled on the policy assessment outcomes. For this purpose, two Multi Discrete-Continuous Extreme Value (MDCEV) models were developed to jointly model the activity type and duration. The first MDCEV model (classic approach) reflected disability as a dummy variable and its interactions with some other variables such as age and employment. The second MDCEV model (separate approach) was estimated only for persons with disabilities. Comparing these two approaches indicated that the way that disability was modeled could affect the results. Statistically significant changes in most coefficients and elasticity values were found. Further, three model transferability metrics (i.e., transferability test statistic, transfer index, and the transfer rho-square) affirm that the separate approach outperformed the classic approach.

Policy assessments should be carried out according to mathematical models that picture the relevant outcomes. Policies that aim at promoting the social involvement of disabled people incur certain costs for the governments that need to be justified. In the absence of routine activity-travel surveys for the disabled community, assessments could be done at almost zero costs by the typical activity-travel surveys that are regularly carried out for general transportation planning purposes. Adopting an improper functional form, however, may result in over/underestimation of the policy outcomes.

This study is an attempt to show that the customary activity-travel surveys and the existing data banks can be used to fine-tune outputs for persons with disabilities by applying appropriate methods. Although the effects of some important variables such as type and severity of disability on activity participation are tangible, it is not possible for every city to collect special data for persons with disabilities. Even though differentiating weekdays and seasons could understandably improve the models, we were bound to the data limitations. Similarly, we lacked land-use variables. Hence, investigating the effect of such variables on activity participation needs to be addressed in future studies. Besides, the way that disability affects the decisions of family members can be considered using the concept of group decision-making, which models the interactions between the group members.

\section{Data availability}

All data used during the study is available on the Metropolitan Travel Survey Archive website (http://www.surveyarchive.org/) for free, and the code of the MDCEV model used in this study is also available in Chandra Bhat's profile as public codes (http://www.caee.utexas.edu/prof/bhat/MDCEV.html).

\section{References}

1. World Bank, Disability inclusion, Last Updated: Sep. 26 (2018). 
https://www.worldbank.org/en/topic/disability\#1. Accessed Mar 20 (2019).

2. Var, T., Yeşiltaş, M., Yaylı, A., et al. "A study on the travel patterns of physically disabled people", Asia Pacific Journal of Tourism Research, 16(6), pp. 599618 (2011).

3. Ermagun, A., Hajivosough, S., Samimi, A., et al. "A joint model for trip purpose and escorting patterns of the disabled", Travel Behaviour and Society, 3, pp. 51-58 (2016).

4. Bureau of Transportation Statistics, U.S. Department of Transportation. "Transportation difficulties keep over half a million disabled at home" (2003). http://www.bts.gov/publications/special_reports_and issues_briefs/issue_briefs/number_03/pdf/entire.pdf

5. Jolly, D., Priestley, M., and Matthews, B. "Secondary analysis of existing data on disabled people's use and experiences of public transport in Great Britain", Disability Rights Commission (2006).

6. Carreno, M., Rye, T., Stradling, S., et al. "Barriers to public transport use: From the perspective of disabled Scottish adults", In 11th World Conference on Transport Research (2007).

7. Mayor of London "Understanding the travel needs of London's diverse communities, disabled people", Transport for London, Tfl no. 10038 (2012).

8. Sweeney, M., Travel Patterns of Older Americans with Disabilities, Washington, DC: US Bureau of Transportation Statistics (2004).

9. Mayor of London "Travel in London: understanding our diverse communities", Transport for London (2015).

10. Taylor, Z. and Józefowicz, I. "Intra-urban daily mobility of disabled people for recreational and leisure purposes", Journal of Transport Geography, 24, pp. 155-172 (2012).

11. Freedman, V.A. and Cornman, J.C. "The panel study of income of dynamics' supplement on disability and use of time (DUST) user guide", Institute for Social Research, University of Michigan, Ann Arbor (2012).

12. Castro, M., Bhat, C.R., Pendyala, R.M., et al. "Accommodating multiple constraints in the multiple discrete-continuous extreme value (MDCEV) choice model", Transportation Research Part B: Methodological, 46(6), pp. 729-743 (2012).

13. Schepers, J. "On regression modelling with dummy variables versus separate regressions per group: Comment on Holgersson et al.", Journal of Applied Statistics, 43(4), pp. 674-681 (2016).

14. Holgersson, H.E.T., Nordström, L., and Öner, Ö. "Dummy variables vs. category-wise models", Journal of Applied Statistics, 41(2), pp. 233-241 (2014).

15. Amendola, A., Dell'Anno, R., and Parisi, L. "Happiness and inequality in European countries: is it a matter of peer group comparisons?", Economia Politica, 36(2), pp. 473-508 (2019).
16. Driver, C. and Muñoz-Bugarin, J. "Financial constraints on investment: Effects of firm size and the financial crisis", Research in International Business and Finance, 47, pp. 441-457 (2019).

17. Loesch, E.K. "Using remote sensing and spatial statistics to characterize increased seismicity in Oklahoma", Doctoral dissertation, Saint Louis University (2018).

18. Gezahegn, T.W., Van Passel, S., Berhanu, T., et al. "Do bottom-up and independent agricultural cooperatives really perform better? Insights from a technical efficiency analysis in Ethiopia", Agrekon, 59(1), pp. 93-109 (2020).

19. Shabanpour, R., Golshani, N., Fasihozaman Langerudi, M., et al. "Planning in-home activities in the ADAPTS activity-based model: A joint model of activity type and duration", International Journal of Urban Sciences, 22(2), pp. 236-254 (2017).

20. Páez, A. and Farber, S. "Participation and desire: leisure activities among Canadian adults with disabilities", Transportation, 39(6), pp. 1055-1078 (2012).

21. World health organization, Model Disability Survey, Accessed on http://www.who.int/disabilities/ data/mds/en/ (May 2018).

22. Statistics Canada, The 2006 Participation and Activity Limitation Survey: Disability in Canada, Accessed on http://www5.statcan.gc.ca/olc-cel/olc.action? objId=89-628-X\&objType=2\&lang =en\&limit $=1$ (April 2018).

23. "Improvement of disability data and statistics: objectives and challenges", United Nation Conference of States Parties to the Convention on the Rights of Persons with Disabilities, Eighth Session, New York, (911 June 2015). www.un.org/disabilities/documents/ COP/crpd_csp_2015_3.doc.

24. Bhat, C.R., Srinivasan, S., and Sen, S. "A joint model for the perfect and imperfect substitute goods case: Application to activity time-use decisions", Transportation Research Part B: Methodological, 40(10), pp. 827-850 (2006).

25. Pinjari, A.R., Bhat, C.R., and Hensher, D.A. "Residential self-selection effects in an activity time-use behavior model", Transportation Research Part B: Methodological, 43(7), pp. 729-748 (2009).

26. Stern, S. "A disaggregate discrete choice model of transportation demand by elderly and disabled people in rural Virginia", Transportation Research Part A: Policy and Practice, 27(4), pp. 315-327 (1993).

27. Schmcker, J.D., Quddus, M., Noland, R., et al. "Estimating trip generation of elderly and disabled people: Analysis of London data", Transportation Research Record: Journal of the Transportation Research Board, (1924), pp. 9-18 (2005).

28. Pinjari, A.R. and Bhat, C.A. "Multiple DiscreteContinuous Nested Extreme Value (MDCNEV) model: Formulation and application to non-worker activity time-use and timing behavior on weekdays", Transportation Research Part B: Methodological, 44(4), pp. 562-583 (2010a). 
29. Sharifi, M.S., Stuart, D., Christensen, K., et al. "Analysis of walking speeds involving individuals with disabilities in different indoor walking environments", Journal of Urban Planning and Development, 142(1), 04015010 (2015).

30. Ravulaparthy, S., Yoon, S., and Goulias, K. "Linking elderly transport mobility and subjective well-Being: A multivariate latent modeling approach", Transportation Research Record: Journal of the Transportation Research Board, 2382, pp. 28-36 (2013).

31. Atlanta Regional Commission. "Regional travel survey final report", Atlanta Regional Commission, GA (2011).

32. Nustats, P.T.V. "Atlanta regional commission regional travel survey final report", Atlanta Regional Commission, pp. 1-207 (2011).

33. Ermagun, A. and Samimi, A. "Mode choice and travel distance joint models in school trips", Transportation, pp. 1-27 (2017).

34. Liu, C., Susilo, Y.O., and Karlström, A. "Jointly modelling individual's daily activity-travel time use and mode share by a nested multivariate Tobit model system", Transportmetrica A: Transport Science, 13(6), pp. 491-518 (2017).

35. Ding, C., Mishra, S., Lin, Y., et al. "Cross-nested joint model of travel mode and departure time choice for urban commuting trips: Case study in MarylandWashington, DC Region", Journal of Urban Planning and Development, 141(4), 04014036 (2014).

36. Habib, K.M.N. "A joint discrete-continuous model considering budget constraint for the continuous part: Application in joint mode and departure time choice modelling", Transportmetrica A: Transport Science, 9(2), pp.149-177 (2013).

37. Jovicic, G. "Activity based travel demand modelling", Danmarks Transp. Skn (2001). https://link.springer.com/content/pdf/10.1007/ s11116-015-9598-x.pdf

38. Eluru, N., Pinjari, A.R., Pendyala, R.M., et al. "Unified model system of activity type choice, activity duration, activity timing, mode choice, and destination choice", Working Paper, the University of Texas at Austin, Texas (2009).

39. Bhat, C.R. "A multiple discrete-continuous extreme value model: Formulation and application to discretionary time-use decisions", Transportation Research Part B: Methodological, 39(8), pp. 679-707 (2005).

40. Jian, S., Rashidi, T.H., and Dixit, V. "An analysis of carsharing vehicle choice and utilization patterns using multiple discrete-continuous extreme value (MDCEV) models", Transportation Research Part A: Policy and Practice, 103, pp. 362-376 (2017).

41. Bhat, C.R. and Sen, S. "Household vehicle type holdings and usage: An application of the multiple discretecontinuous extreme value (MDCEV) model", Transportation Research Part B: Methodological, 40(1), pp. $35-53$ (2006).
42. Ma, J. and Ye, X. "Modeling household vehicle ownership in emerging economies", Journal of the Indian Institute of Science, 99(4), pp. 647-671 (2019).

43. Ma, J., Ye, X., and Pinjari, A.R. "Practical method to simulate multiple discrete-continuous generalized extreme value model: Application to examine substitution patterns of household transportation expenditures", Transportation Research Record, 2673(8), pp. 145-156 (2019).

44. Zong, W., Zhang, J., Yu, B., et al. "Energy consumption in the transport and domestic sectors: A household-level comparison between capital cities of Japan, China, and Indonesia", In Transport and Energy Research, pp. 73-98, Elsevier (2020).

45. Bhat, C.R. "The multiple discrete-continuous extreme value (MDCEV) model: Role of utility function parameters, identification considerations, and model extensions", Transportation Research Part B: Methodological, 42(3), pp. 274-303 (2008).

46. Bhat, C.R. "MDCEV with Outside Good", Public Code, Available on http://www.caee.utexas.edu/prof/ bhat/CodeRepository/CODES/MDCEV_Files /MDCEV_With_Outside_Good.zip (2008).

47. Shamshiripour, A. and Samimi, A. "Estimating a mixed-profile MDCEV: Case of daily activity type and duration", Transportation Letters, 11(6), pp. 289-302 (2019).

48. Pinjari, A.R., and Bhat, C.R. "An efficient forecasting procedure for Kuhn-Tucker consumer demand model systems: Application to residential energy consumption analysis", Technical Paper, Department of Civil and Environmental Engineering, University of South Florida, pp. 263-285 (2010b).

49. Atherton, T.J. and Ben-Akiva, M. "Transferability and updating of disaggregate travel demand models", Transportation Research Record, 610, pp. 12-18 (1976).

50. Koppelman, F.S. and Wilmot, C.G. "Transferability analysis of disaggregate choice models", Transportation Research Record, 895, pp. 18-24 (1982).

51. McFadden, D. "Conditional logit analysis of qualitative choice behavior", P. Zarembka (Ed.), Frontiers in Econometrics, New York: Academic Press, pp. 105142 (1974).

52. Milakis, D. and van Wee, B. "Implications of vehicle automation for accessibility and social inclusion of people on low income, people with physical and sensory disabilities, and older people", In Demand for Emerging Transportation Systems, Antoniou, C., Efthymiou, D., Chaniotakis, E., Eds, Elsevier: Amsterdam, The Netherlands, pp. 61-73, ISBN (2020).

53. Bennett, R., Vijaygopal, R., and Kottasz, R. "Willingness of people who are blind to accept autonomous vehicles: An empirical investigation", Transportation Research Part F: Traffic Psychology and Behaviour, 69, pp. $13-27$ (2020). 
54. Queensland Health, Medical Aids Subsidy Scheme (MASS), "Vehicle Options Subsidy Scheme (VOSS) Guidelines", Accessed on https://www.ideas.org.au /uploads/resources/769/VOSS\%20Guidelines\%20 QLD.pdf (April 2018).

55. Ren, G., Zhang, T., Xu, L., et al. "Transportation demands of low-mobility individuals: Case study in wenling, China", Journal of Urban Planning and Development, 144(4), pp. 05018019 (2018).

56. Jansuwan, S., Christensen, K.M., and Chen, A. "Assessing the transportation needs of low-mobility individuals: Case study of a small urban community in Utah", Journal of Urban Planning and Development, 139(2), pp. 104-114 (2013).

57. Bezyak, J.L., Sabella, S., Hammel, J., et al. "Community participation and public transportation barriers experienced by people with disabilities", Disability and Rehabilitation, 42(23), pp. 3275-3283 (2020).

58. CRT (Country Roads Transit) agency, Accessed on https://countryroadstransit.com/about/ (April 2018).

59. Pfeiffer, B., Sell, A., and Bevans, K.B. "Initial evaluation of a public transportation training program for individuals with intellectual and developmental disabilities", Journal of Transport and Health, 16, 100813 (2020).

60. Government of Canada "Canada Student Grant for Students with Permanent Disabilities", Accessed on https://www.canada.ca/en/employment-socialdevelopment/services/education/grants/disabilities. html (April 2018).

61. University of Iowa. "Transit Services for Persons with Disabilities", Accessed on https://transportation.uiowa.edu/transit-servicespersons-disabilities -bionic-bus (April 2018).

\section{Biographies}

Shaghayegh Vosough is a PhD candidate in Transportation Planning at Sharif University of Technology. She spent her visiting program at University of British Columbia as a Research Assistant (2018-2020). Her research interests include the impact of transportation on health and the environment, traffic congestion and road pricing, and transportation and sustainable development.

Amir Samimi is an Associate Professor at the Civil Engineering Department at Sharif University of Technology. He received his $\mathrm{PhD}$ in Transportation Planning from University of Illinois at Chicago in 2010. His research is focused on travel demand modeling, logistics and supply chain management, freight transportation systems, and applied econometrics in transportation. 